\title{
Re-thinking South African dentists' role in a pandemic
}

SADJ November 2020, Vol. 75 No. 10 p575 - p579

RZ Adam

\begin{abstract}
Mass disasters such as terrorism, earthquakes and virus outbreaks challenge any healthcare system. Response teams to disasters typically consist of health professionals, local government, corporations, and community organizations, academics and the scientific community. Dentists or dental hygienists have traditionally only played a role in the identification of victims or in the treatment of facial trauma in disaster response.
\end{abstract}

In South Africa, the response was mainly driven by medical professionals. Collaborative practice supported by inter-professional education may offer a solution to assist countries struggling with access to healthcare and overburdened health systems. In addition, revisiting the dentists' role in prioritising oral health and its relationship with general health and well-being is much needed. This short article provides a perspective on the role of South African dentists' contribution to health during a pandemic.

\section{Keywords}

Pandemic, disaster, collaborative practice, inter-professional education, responders, public health, dental schools, models.

\section{Re-thinking South African dentists' role in a pandemic}

Health care workers are at the forefront of any disaster response- man-made or natural. Worldwide there has been an increasing number of natural disasters and terrorist events resulting in a need for a mass casualty response. The Middle East respiratory syndrome (MERS) in 2012, the Ebola outbreak (2014), the Zika virus outbreak (2015) and the current Corona virus challenge healthcare systems.

These events place a huge burden on emergency services locally and nationally. The demands range from emergency medical rescue systems, medical resources, accurate information and a trained workforce. Comprehensive response plans include 'interdisciplinary health professionals, local government, corporations, and community organisations including non-profit organisations,

Author affiliations:

Razia Z Adam: BChD, PG Dip, MSc, PhD, BAAP awardee (NRF), Senior lecturer, Restorative Dentistry, Faculty of Dentistry, University of the Western Cape, Cape Town, South Africa.

ORCID Number: 0000-0002-2645-9878

Email: rzadam@uwc.ac.za academia and the scientific community'. ${ }^{1}$ The Health Professions Council of South Africa published a guidance document to all healthcare practitioners stating that 'practitioners may be required to depart from their established procedures, although this should be done responsibly, reasonably and in the best interest of patients'.2 Eliav (2017) proposed that the role of dentists extend beyond traditional dentistry by virtue of the education they receive. ${ }^{3} \mathrm{He}$ also called on dentists to lead collaborative practices to improve the health of the communities. The purpose of this paper is to highlight the need to re-think dentists' contribution to health in South Africa.

\section{Involvement of dentists in previous disasters}

Traditionally first responders usually include doctors, nurses, and emergency medical technicians or paramedics. Morlang first suggested the potential role of an oral health care worker as part of a civilian and military disaster response team in 1996. ${ }^{4}$ The 1980 MGM Grand Hotel and Casino fire in Las Vegas, was the earliest report of dental hygienists' role in a mass fatality incident. ${ }^{5}$ The dental hygienists assisted in obtaining and verifying post-mortem records and radiographic imaging of the victims.

In 2001, Bacillus anthracis spores were spread through mail in the United States of America (USA). 18 persons were infected and five deaths were reported. 6 The response from patients and dental professionals indicated a need for accurate information about the diagnosis, management and prevention strategies of anthrax infections. It is also highlighted the lack of preparedness in the event of a disaster. The American Dental Association convened a consensus workshop on Dentistry's response to bioterrorism in 2002. Zohn et al. reported that 350 dentists and dental auxiliaries assisted with the forensic identification of victims of the World Trade Centre attacks. ${ }^{7}$ Following the seaquake in South East Asia in $2004,80 \%$ of the non-Thai victims were identified by dental information. ${ }^{8}$

In 2006, the scope of practice in dentistry was modified in Illinois, USA. ${ }^{4}$ The Illinois Dental Practice Act describes the dental emergency responder (DER) -dentist or dental hygienist- as "acting within the bounds of his or her license when providing care during a declared local, state or national emergency." The DER is "appropriately certified in emergency medical response, as defined by the Department of Public Health." ${ }^{4}$ 
In 2007, the American Dental Association resolved to promote dentists' role in a disaster with the following: education and training programmes to help dental volunteers during public health emergencies, protection of dentists' licensing for treatment of public health emergencies across state lines, and credentialing systems affecting oral health care workers interested in supporting a public health response.

In July 2009, the World Health organisation alerted us to the H1N1 pandemic. The Swine Flu or Influenza A flu is an acute respiratory disease of swine origin. The highly contagious virus was transmitted by person to person and droplet spread. ${ }^{9}$ The virus spread rapidly and the CDC estimated that between 151,700-575,400 people worldwide died from (H1N1). In May 2009, a group of dental students were infected resulting in the closure of the Harvard School of Dental Medicine. ${ }^{9}$ By October 2009, at least four vaccines were available. Due to the occupational risk of exposure, healthcare workers were recommended to be immunised. In the state of Massachusetts, USA, dentists were deputised to administer immunisations. ${ }^{10}$

In 2013, dentists were included into the Pandemic and All-Hazards Preparedness Reauthorization Act (PAHPA). Dentists may now be included as disaster response public health responders. This legislation also allows dental schools to receive funding to train public health and medical response workers. ${ }^{11}$

\section{The role of dental schools in a disaster}

Dentists do play an important and effective role in disasters but it has largely been limited to processing missing persons and identifying remains. A survey of deans of medical and dental schools and presidents of medical and dental societies concluded that dentists are not only adept to act as first responders in a mass casualty event but they also have an ethical responsibility to be involved in response to a disaster. ${ }^{12}$

Dental schools have a responsibility to provide accurate information to the students, patients and to the communities they serve. Academics at dental schools are well placed to ensure that oral health care workers are appropriately trained to respond to the disaster. Simultaneously to the ADA 2002 consensus workshop, the New York University College of Dentistry proposed that the dental school curriculum include bioterrorism studies and training and should prepare dentists to respond to a public health disaster. ${ }^{13}$ The plan covered all stages of education: predoctoral basic competencies, postdoctoral training competencies, elective continuing education and advanced programmes for interested persons.

Psoter et al. proposed educational objectives for hospital-based dentists to prepare them to contribute to a hospital disaster response. ${ }^{14}$ They concluded that many hospital-based dentists already receive an integrated training by medical professionals and they could serve as additional capacity or be redeployed. In the present COVID-19 pandemic, oral surgery residents at Rutgers University volunteered to treat patients at the Emergency room as there was a shortage of medical staff. ${ }^{15}$

\section{Inter-professional collaborative practice}

Interprofessional education (IPE) is a learning strategy to accomplish collaborative practice. ${ }^{16}$ IPE creates a platform to share knowledge and skills among professions. The World Health Organisation (WHO) defined IPE as 'students from two or more professions who learn about, from and with each other to enable effective collaboration and improve health outcomes'. ${ }^{17}$

Collaborative practice is defined as a dynamic process when "multiple health workers from different professional backgrounds work together with patients, families, carers and communities to deliver the highest quality care". ${ }^{18}$ A study of collaborative practises in American dentistry identified three main benefits of collaborative practice: 1. Improved access to healthcare.

2. Reduced costs and increased productivity.

3. Better quality of services.

Collaborative practice allows participants to merge their expertise with others resulting in improved outcomes. Enablers to collaborative practice include: 'organisational mandate, clear sets of responsibilities, a team structure and shared goals and outcomes as well as a supportive environment'. ${ }^{16}$

Dentists are capable of detecting, screening and preventing systemic conditions. There has been mounting evidence of the relationship between oral health and general overall health. For instance, oral health has been linked to an increased risk for cardiovascular disease, diabetes and Alzheimer's disease. In addition, patients taking medications for chronic conditions may suffer from oral conditions as a result. This further illustrates the need for a good collaborative relationship between dentists and medical professionals as it has potential to affect patient outcomes.

In 2015, the Federation Dentaire Internationale (FDI) published its report 'Optimal Oral Health through InterProfessional Education and Collaborative Practice'. ${ }^{16}$ The organisation believes that dentists should lead the process of interprofessional collaboration. Effective relationships with medicine, public health and all other health Practitioners are essential.

The Interprofessional Education Collaborative (IPEC) developed core competencies for interprofessional collaborative practice. These were updated in 2016 and defined as:

Competency 1: Work with individuals of other professions to maintain a climate of mutual respect and shared values.

Competency 2: Use the knowledge of one's own role and those of other professions to appropriately assess and address the health care needs of patients and promote and advance the health of populations.

Competency 3: Communicate with patients, families, communities, and professionals in health and other fields in a responsive and responsible manner that supports a team approach to the promotion and maintenance 
of health, and the prevention and treatment of disease.

Competency 4: Apply relationship-building values and the principles of team dynamics to effectively plan, deliver and evaluate patient/population-centered care, and population health programs and policies that are safe, timely, efficient, effective and equitable. ${ }^{19}$

The most important outcome of this initiative is to further enable the development of a workforce which will optimise health care and advance population health.

\section{Current practices of IPE in dentistry}

A 2012 survey reported IPE opportunities in American dental education at 34\% and eventually in 2015 it was recorded at $69 \% .^{19}$ By 2015, 90\% of dental schools in America offered IPE to students and $75 \%$ also offered training to dental educators. The American Dental Association Commission on Dental Accreditation for dental education programmes revised standards in 2016 to include a competency on collaborative practice.

A 2020 national survey of American dental schools reported that $96 \%$ of the schools engaged in clinical and non-clinical inter-professional sessions. ${ }^{20}$ The development, implementation and early results of an IPE curriculum at a dental school was reported on in 2020. ${ }^{21}$ In this model, dental students were placed at a community health care facility and they had the opportunity to perform head and neck examinations as well as intra oral checks. This was shared with medical students and other allied care students.

Patients were also referred for further oral care. Similarly, medical students rotated in dental emergency and treatment planning clinics allowing them to share their knowledge about systemic conditions. ${ }^{21}$ While there were challenges and the impact on patient outcomes are not clear at this stage, this example of IPE could have important lessons for dental education especially in areas where access to healthcare is problematic.

Locally, Filies reported 'that there are no South African studies currently in the literature that provide evidence of IPE core competency development in curriculum design'. ${ }^{22}$ Filies advocates the scaffolding of competencies along the continuum of learning and appropriately aligned assessments. ${ }^{22}$

In South Africa, there is a paucity of literature around IPE and dental education although it has been identified as a competency by the HPCSA. Moodley and Singh conducted research around the opportunities for interprofessional collaboration for dental therapy and oral hygiene students at the University of the KwaZulu Natal. ${ }^{23}$ They suggest that ideal opportunities would be involvement in community-based disease prevention and health promotion interventions.

\section{Proposed roles for dentists in a pandemic}

During a bioterrorist attack, pandemic or disaster, local health services and hospitals may be overwhelmed or damaged rendering them ineffective. Worldwide, health- care workers account for $10 \%$ of global COVID-19 infections. ${ }^{24}$ While in South Africa, Health Minister Zweli Mkhize reported that 'more than 24000 health-care workers have been infected with Covid-19, while another 181 have succumbed to the virus'. ${ }^{25}$ The current Coronavirus pandemic provides a background for collaborative practice.

In South Africa, the White paper and Act on Disaster Management define the roles of Local Authorities as well as Provincial and National government in disaster management. The HPCSA may register medical practitioners or dentists as volunteer services to participate in health care relief activities under supervision temporarily. In addition, some healthcare professionals such as oral hygienists in independent practice in South Africa are required to have a Level three First aid qualification but this does not include dentists.

Dentists in South Africa may contribute to the health services during a disaster in the following manner:

\section{Prior to an attack:}

Biologic weapons may be classified as bacterial agents, viral agents and biological toxins. Traditionally, dentists would not be familiar with the effect they may have on the human body. Education programmes for all oral health care workers and the public on the pathogens used in bioterrorism and the oral manifestations of such a disease would be essential. ${ }^{6}$

- All dentists should be required to maintain a Level 3 First aid qualification.

- Expose dentists and dental students to disaster medicine.

- The local dental association should develop up-to-date quick reference guides for distribution. These guides should provide dentists with necessary information to respond appropriately. ${ }^{6}$

- Dentists should be included in an integrated community response plan. ${ }^{6}$

- Dental surgeries are ideally located within communities which could serve as stockpiling sites for materials and supplies. ${ }^{6}$

- Dentists should form part of a network of healthcare practitioners in their area of practise.

\section{During an attack:}

Dental surgeries contain sterilisation equipment, air and gas lines, suction equipment, radiographic equipment, instruments and needles. If local hospitals or clinics are overwhelmed these facilities could be used as minihospitals. ${ }^{6}$

Surveillance and notification: Dentists as community clinicians are often well placed to detect characteristic oral and cutaneous lesions and report it to the health authorities. Unusual patient and employee attendance patterns may be the warning signs in a community of impending threats. ${ }^{0}$

Diagnosis and monitoring: Dentists may collect salivary and nasal swabs for the diagnosis of such an attack. ${ }^{6}$ 
Referral: Dentists are able to refer patients which require further management or who need specialist treatment. ${ }^{6}$

Immunisations: Organisations may expand their workforce capacity by recruiting health care workers to assist. If rapid vaccination of the population is required, dentists may be recruited to assist in the immunisation programme. $^{6}$

Medications: Dentists could be asked to assist in dispensing of preventive medication or the prescription and dispensing of medications to the public. Additionally, they may be used to repackage medications for dispensing. Dentists are also capable of monitoring patients for adverse events or side effects to medication. ${ }^{6}$

Triage: During a disaster response, the health system may become overburdened with casualties. In this instance, it is essential that patients are triaged correctly so that priorities for treatment may be established. Dentists with the appropriate training may assist in this process. ${ }^{6}$

Medical care augmentation: Dentists or dental specialists may have the training to provide the following services:

- Starting intravenous lines.

- Performing appropriate surgery and surgery.

- Shock management.

- Stabilising patients.

- Collecting blood samples.

- Taking medical histories.

- Providing cardiopulmonary resuscitation. ${ }^{6}$

In the case of a pandemic, the establishment of a quarantined area or the infection of large numbers of medical personnel may limit the services available to a community. Dentists may be recruited to provided primary health care if they have not been affected. ${ }^{6}$

Decontamination and infection control: Dentists and dental assistants are knowledgeable in infection control and decontamination. They are a valuable asset to assist medical personnel and to educate the community. ${ }^{6}$

Oral and facial health care: Facial injuries are common trauma injuries in earthquakes. Thus dentists and oral and maxillofacial surgeons play an important part of the team.26 Patients experiencing pain or signs of infection may need to seek dental treatment. It is important that emergency dental treatment be made available with appropriate measures in place to protect patient and health care workers.

Currently, the Corona virus pandemic is an infectious respiratory disease which may result in the aspiration of oral bacteria into the respiratory tissues. Recent evidence confirms the relationship between oral bacteria and pneumonia. ${ }^{27}$ It also confirms that oral health and oral hygiene habits may affect the incidence and outcomes of patients with pneumonia.

After the attack: Dentists trained in forensic odontology may assist response teams. They may also continue to monitor and provide local surveillance. ${ }^{6}$

\section{Recommendations for the future}

The onset of the Corona pandemic has challenged many academic institutions worldwide. Dental schools have been particularly affected as the risk for the dental profession is very high with the performance of aerosol generating procedures. This has resulted in the closure of many dental clinics restricting dental care to emergencies only. Dentists' response to a pandemic or disaster could positively impact patient outcomes if the profession is able to leverage its contribution to overall health. Investing in interprofessional education models for health professions in South Africa could address issues of shortage of healthcare personnel and accessibility to healthcare.

\section{References}

1. Lyon L. Dentists' Role in Interprofessional Education and Practice. 2020. p. 1-11.

2. Covid-IT, African S, Africa S, et al. Covid-19 Outbreak in South Africa: 2020.

3. Eliav E. We can do more: The role of dentists extends beyond traditional dentistry. Quintessence Int. 2017; 48(10): 775.

4. Colvard MD, Lampiris LM, Cordell GA, James J, Guay A, Lee $\mathrm{M}$, et al. The dental emergency responder: Expanding the scope of dental practice. J Am Dent Assoc. 2006.

5. Bruhn AM, Newcomb TL, Sheth-Chandra M. Assessment of Mass Fatality Preparedness and Response Content in Dental Hygiene Education. Vol. 4608, Health Sciences Building. 2016.

6. Guay $\mathrm{AH}$. Dentistry's response to bioterrorism: a report of a consensus workshop. J Am Dent Assoc. 2002; 1181-7.

7. Zohn HK, Dashkow S, Aschheim KW, et al. The odontology victim identification skill assessment system. J Forensic Sci. 2010.

8. Schuller-Götzburg P, Suchanek J. Forensic odontologists successfully identify tsunami victims in Phuket, Thailand. Forensic Sci Int. 2007; 171(2-3): $204-7$.

9. Pitak-Arnnop P, Schubert S, Dhanuthai K, et al. Swine-origin H1N1 influenza A virus and dental practice: A critical review. Vol. 14, Clin Oral Investig. 2010; 11-7.

10. Glick M. Editorial: Do dentists have a role in fighting the latest H1N1 pandemic? J Am Dent Assoc. 2009; 140(9): 1072-4.

11. New Law Incorporates Dentists in Emergency Response Plans [Internet]. American Dental Association. [cited 2020 Aug 17]. Available from: https://www.ada.org/en/press-room/ news-releases/2013-archive/march/new-law-incorporatesdentists-in-emergency-response-plans.

12. Psoter WJ, Park PJ, Boylan RJ, Morse DE, Glotzer DL. National emergency response programs for dental health care professionals. J Am Dent Assoc. 2008; 139(8): 1067-73.

13. Glotzer DL, Rekow ED, More FG, Godder B, Psoter W. All Hazards Training: Incorporating a Catastrophe Preparedness Mindset into the Dental School Curriculum and Professional Practice. Vol. 51, Dent. Clin N Am. 2007; 805-18.

14. Psoter WJ, Herman NG, More FG, Park P, Robbins M, Rekow ED, et al. Proposed Educational Objectives for Hospital-Based Dentists During Catastrophic Events and Disaster Response. J Dent Educ. 2006; 70: 835-43.

15. Dental School Residents Volunteer on the Front Lines of the COVID-19 Pandemic | Rutgers University [Internet]. Available from: https://www.rutgers.edu/news/dental-school-residentsvolunteer-front-lines-covid-19-pandemic.

16. FDI World Dental Federation. Optimal Oral Health Through Inter-Professional Education and Colloborative Practice. 2015.

17. World Health Organization. Framework for Action on Interprofessional Education \& Collaborative Practice Health Professions Networks. World Health Organization. 2010. 
18. Interprofessional Educational Collaborative. Competencies for Interprofessional Collaborative Practice: 2016 Update. Interprofessional Educ Collab. 2016; (May 2011): 10-1.

19. Jiang T, Tavares MA, Ticku SH, Riedy CA, Silk HJ, Sullivan KM, et al. Interprofessional education in dental schools: Results of a national survey. J Interprofessional Educ Pract. 2020; Mar 1; 18: 100256.

20. Sabato EH, Fenesy KE, Parrott JS, Rico V. Development, implementation, and early results of a 4-year interprofessional education curriculum. J Dent Educ. 2020; May 2.

21. Filies GC. Development of an Interprofessional Education Model that Aims to Instil the Core Competencies of Interprofessional Collaborative Practice in Allied Health Students Curriculum. 2017.

22. Moodley I, Singh S. Creating opportunities for interprofessional, community-based education for the undergraduate dental therapy degree in the School of Health Sciences, University of KwaZulu-Natal, South Africa: Academics' perspectives. African J Heal Prof Educ. 2018; 10(1): 19.
23. Deutsche Welle. Coronavirus latest: WHO says health workers account for $10 \%$ of global infections. Deutsche Welle. 2020. Available from: https://www.dw.com/en/coronaviruslatest-who-says-health-workers-account-for-10-of-global-infections/a-54208221.

24. Covid-19 in SA:24. 104 health-care workers infected, 181 dead - Health Minister. 2020. Available from: https://www.iol. co.za/news/south-africa/covid-19-in-sa-24-104-health-careworkers-infected-181-dead-health-minister-ef0da1c3-b50b48cc-8793-4a86ceebedb5.

25. Wang L, Wei J, He L, et al. Dentists' Role in Treating Facial Injuries Sustained in the 2008 Earthquake in China. J Am Dent Assoc. May 2009; 140(5): 543-9.

26. Manger D, Walshaw M, Fitzgerald R, et al. Evidence summary: The relationship between oral health and pulmonary disease. Br Dent J. 222(7): 527-33.

\section{Do the CPD questionnaire on page 591}

The Continuous Professional Development (CPD) section provides for twenty general questions and five ethics questions. The section provides members with a valuable source of CPD points whilst also achieving the objective of CPD, to assure continuing education. The importance of continuing professional development should not be underestimated, it is a career-long obligation for practicing professionals.

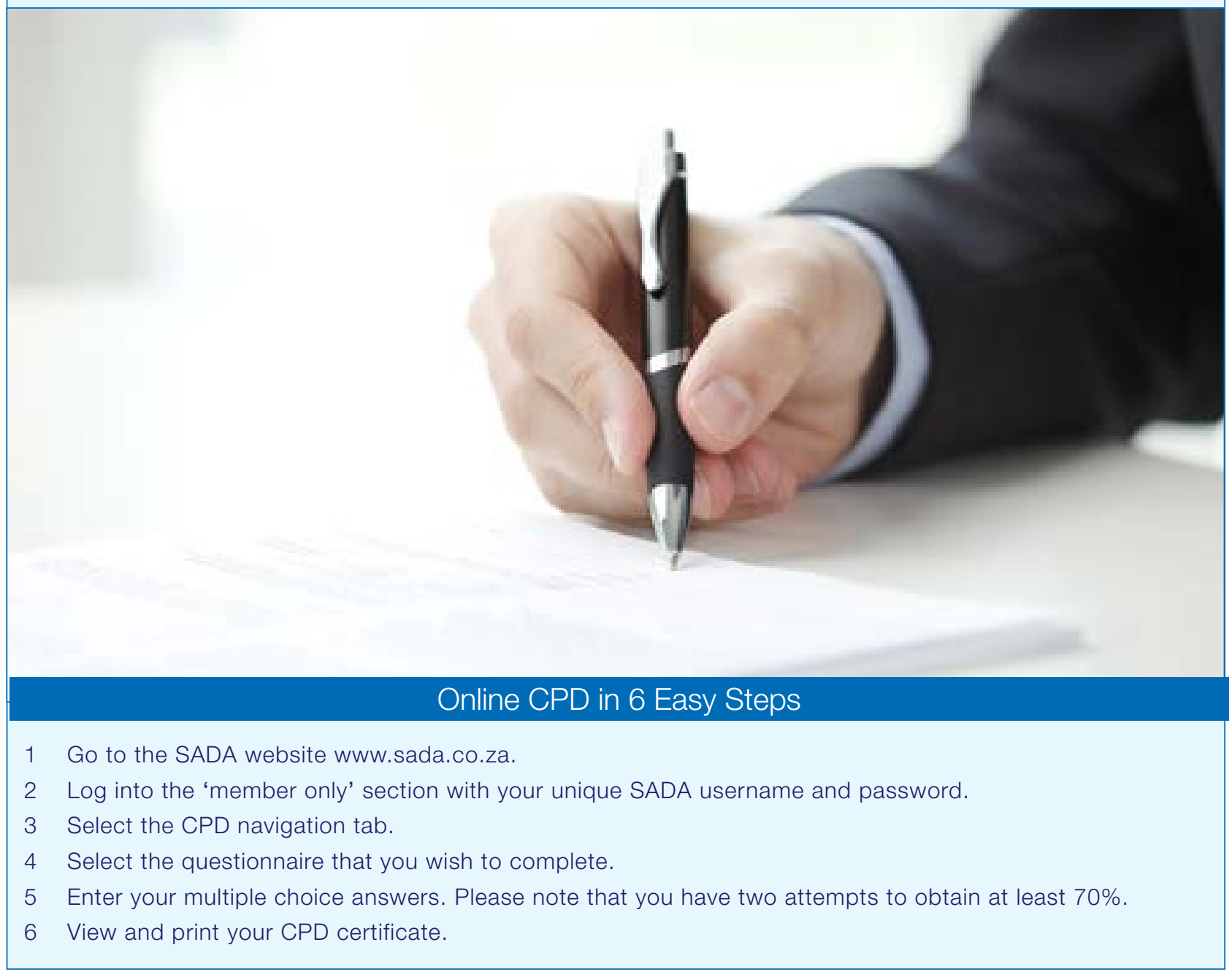

